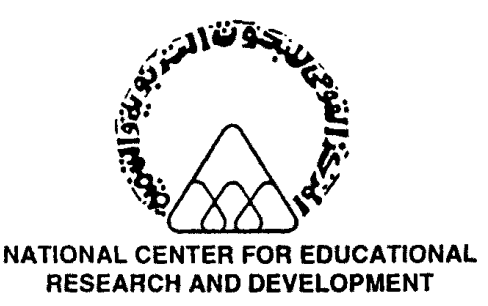

\title{
On the Proving of GeoGebra
}

\author{
إعـاد \\ Fumiya Iwama $^{1}$, Yuji Shinoda ${ }^{2}$ \\ ${ }^{1}$ Graduate School of Natural Science, Konan University \\ ${ }^{2}$ Center for Education in General Studies, Konan University \\ 1d1623001@konan-u.ac.jp, ${ }^{2}$ shinoda@ center.konan-u.ac.jp
}

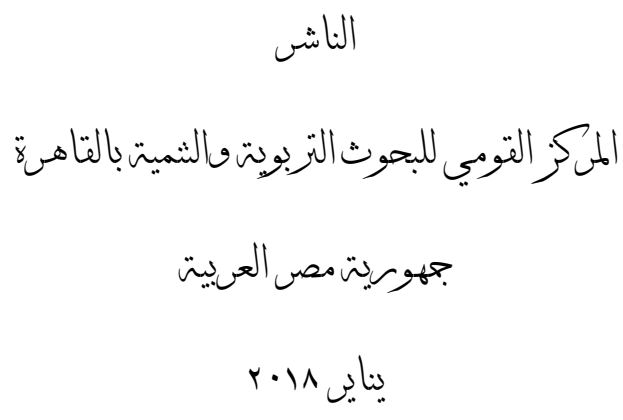




\title{
GeoGebra حول إثباتات برنامج الرياضيات التفاعلى جيوجييرا
}

\author{
Fumiya Iwama $^{1}$, Yuji Shinoda ${ }^{2}$ \\ ${ }^{1}$ Graduate School of Natural Science, Konan University \\ ${ }^{2}$ Center for Education in General Studies, Konan University

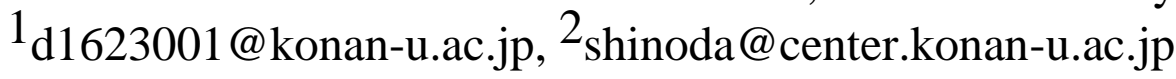

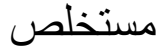

على الرغم من صعوبة المحتوى المنطق بمشكلات الإثبات للمبنتئين، والذى يمكن أن يؤكد جوهر التطور المنطقى، فإن الجهود المبذولة لاستخدام برنامج الرياضيات الثفاعلى جيوجييرا فى العلن، أو ضمنيًا قد تسهل حل مثل هذه المثكلات. والموقع الرسمي لبرنامج الرياضيات الثفاعلى جيوجيرا يقدم وظيفة الإثبات، مما يثير إلى أن مشروع برنامج جيوجييرا برنامج طموح فى هذا الهجال ليس فقط ولكن العلاقة بين متغيرين، ولكن أيضا لإثات المشكلات الهنسية. ونحن نعتبر كيفية استخام قارة استخدام الإثبات الهندى استخدام الكمبيوتر في التعليم. وبعبارة أخرى، نحن نختبر نوعية المحتوى، وكيفية الجمع بين وظائف التحقق الكقدة، والثروط التي يجب أن يسحح للطلاب التطلم عن طريق التجربة والخطأ، وتعرض الطلاب للأنثطة الذهنية الرياضية. ومع ذلك فمن خلال معالجة هذه المشكلة، فإنه من الضروري مناقثة ما إذا كانت متل هذه الخبرات التطليمية ستكون ذات مغزى في المقام الأول، فضلا عن نوع وظيفة الإثبات التى بمكن تقديمها من خلال برنامج الرياضيات التفاعلى جيوجييرا، بعد اختبار الاستراتيجية المترحة لاستخدام وظيفة الإثبات، متل كيفية استخدام البرمجيات ذات وظيفة النحقق فى التعليم، ونختبر نوعية وظيفة الإثبات النى يمكن أن يقدها برنامج جيوجييرا، وكنلك فاعلية وإمكانية استخدام برنامج جيوجيبرا فى الاثبات الهنسي. 


\title{
On the Proving of GeoGebra
}

\author{
Fumiya Iwama1, Yuji Shinoda2 \\ 1Graduate School of Natural Science, Konan University \\ 2Center for Education in General Studies, Konan University \\ 1d1623001@konan-u.ac.jp,2shinoda@center.konan-u.ac.jp
}

\begin{abstract}
$\underline{\text { Abstract }}$
Although contents related to proof problems, which can clarify the essence of logical development, are difficult for beginners, efforts to use GeoGebra explicitly or implicitly may facilitate the solution of such problems. The official website of GeoGebra introduces the proving function, suggesting that the GeoGebra project is ambitious, not only for plotting, but also for proof of geometric problems. Here, we consider how to use the geometric proof ability of a computer in education. In other words, we examine the type of subject matter, how to combine provided certification functions, the conditions under which students should be allowed to learn by trial and error, and the exposure of students to mathematical intellectual activity. However, in addressing this problem, it is necessary to discuss whether such
\end{abstract}


learning experiences will be meaningful in the first place, as well as what type of proof function can be provided by GeoGebra. Therefore, in the present paper, after examining the usage strategy of the proof function, such as how software with a certification function can be used for education, we examine the type of proof function that GeoGebra can provide and consider the significance and feasibility of using GeoGebra for geometric proof. 


\section{Complete proof and incomplete but valid proof}

G. Polya proposed the concepts of a complete proof and an incomplete but effective proof[1]. He stated that incomplete proofs and complete proofs are separate things. An incomplete proof is not a substitute for a complete proof, and a complete proof is a logical system. He abandoned the concept of the complete proof and sought only superficial utility.

Moreover, even though potentially troublesome, the best way to solve a contradiction is to make good use of incomplete proofs. In the eyes of strict logicists, an incomplete proof is not a proof. Therefore, it is necessary to clearly distinguish between an incomplete proof and a complete proof. Incomplete proofs are useful if used well and in the correct place. Incomplete proofs are not substitutes for complete proof, but rather provide relevance to the matter at hand.

In this way, even a proof may be an incomplete proof, he argued that there are cases in which incomplete proofs can function effectively.

GeoGebra is a software package that provides a user-friendly figure drawing function. We hope to propose a learning approach that uses valid proofs, even if they are incomplete, that will be of interest to learners and help them to internalize an understanding of the subject matter. We believe that the figuredrawing component of GeoGebra will be useful in exploring this new use of GeoGebra. Considering the proof based on GeoGebra drawing, for example, when a triangle is drawn with three points, $\mathrm{A}, \mathrm{B}$, andC, the learner understands that $\triangle \mathrm{ABC}$ is not collapsed on one line. On the other hand, mathematically, without adding appropriate conditions to $\mathrm{A}, \mathrm{B}$ andC, connecting these points will not guarantee the formation of a triangle. Given the users experience of proof based on GeoGebra drawing, it is expected to be difficult to achieve a satisfactory level of rigor equivalent to that of a complete mathematical proof that is made up of logical expressions. However, if we can evaluate a drawing as "Correct in this figure" or "Parallel in this drawing", for example, then the proof can be greatly simplified by defining the condition such that "Each 
condition is as shown in this figure". This concept, i.e., the incomplete but valid proof, is thought to be a stimulus for useful understanding.

\section{Currentprover behavior}

Based on the discussion in the previous section, regarding the proof function, a function that is sufficient to deal with, e.g., how to connect a valid and incomplete proof to a complete proof in GeoGebra, is necessary. On the other hand, for the prover, which is a gimmick function of GeoGebra, unless the type of function and its behavior are clarified, it is impossible to create a base example for discussing teaching strategies. Therefore, in the present paper, we attempt to clarify the situation of the proof function of the prover in order to examine how to approach the proof problem. Specifically, we examine what types of things are possible in the current version and how the function expansion required for teaching can be realized. Here, we attempt to clarify the behavior of the current prover. As of November 10, 2017, the GeoGebra wiki has a Theorem Proving section, and this section was most recently updated on June 2015[2]. The behavior of the prover is still under development, and the constraints of the prover are considered in this section. and Four provers are implemented: Recio, Botana, Puresymbolic, and OpenGeoProver. Moreover, although each prover has functional constraints, information is not displayed even if following been the explanation link of the function constraint. [Your intended meaning is unclear. Please try to rephrase.] Therefore, in order to clarify the behavior of the proving function, we verify the operation using ver. 5.0.396, which was the latest version as of November 10, 2017. The performance of the proving function in cooperation with the Relation function was the subject of interest.

We input the program in which the prover operates.

$$
\begin{aligned}
& \mathrm{A}=(1,1) \mathrm{B}=(1,-1) \mathrm{C}=(-1,1) \mathrm{D}=(-1,-1) \\
& \mathrm{f}=\operatorname{line}[\mathrm{A}, \mathrm{B}] \mathrm{g}=\text { line}[\mathrm{C}, \mathrm{D}] \\
& \text { Relation[f,g] Relation[A,f ] } \\
& \text { Relation[AB,CD] }
\end{aligned}
$$


Here, four points were placed around the origin, and a straight line was drawn vertically. We investigated the relationship between straight lines, the relationship between a point and a straight line, and the relationship between line segments. The operation results are shown in Table 1. When Relation[f, g] is executed, GeoGebra automatically outputs the investigation result of the relationship indicating that $f$ and $g$ are parallel. If the "details" button is clicked, the prover will operate and the result of evaluation will be displayed. The results obtained for the inputs are listed in Table 1.

Table 1 Behavior of ver. 5.0.396 of the proving function

\begin{tabular}{|c|l|}
\hline Syntax & Detailed screen output \\
\hline Relation[f, g] & f and g are parallel. (But generally not correct) \\
\hline Relation[A, f] & A is on f. (Always correct) \\
\hline Relation[AB, & $\begin{array}{l}\text { Distance[A, B] and Distance[C, D] are equal. } \\
\text { (But generallynot correct) }\end{array}$ \\
CD]
\end{tabular}

On the other hand, if we can clarify how the expression "but generally not correct" in Table 1 is obtained, hints for strategies to use GeoGebra to solve proof problems are obtained. However, in the standard state, further information cannot be obtained, and it is impossible to infer the processing performed internally.

Regarding this proof result, a previous version of GeoGebra has been used in previous research. Table 2 shows the behavior of the prover at the beginning of 2017. 
Table 2 Behavior of the prover at the beginning of 2017 [3]

\begin{tabular}{|c|c|c|}
\hline and & $\begin{array}{l}\text { (A) Place dots with } \\
\text { mouse }\end{array}$ & $\begin{array}{l}\text { (B) Enter coordinat } \\
\text { from the input bar }\end{array}$ \\
\hline $\begin{array}{l}\mathrm{A}=(-3,3), \quad \mathrm{B}= \\
(-3,-3), \mathrm{C}=(3,-3), \mathrm{D} \\
=(3,3), \quad \mathrm{f}=\operatorname{Line}[\mathrm{A}, \mathrm{B}], \\
\mathrm{g}=\text { Line[C, D] }\end{array}$ & $\begin{array}{l}\text { Relation[f, g]: } \quad 1, \quad \mathrm{R} \\
\text { Relation[A, f]: } 2, \quad \mathrm{~B} \\
\text { Relation[AB, CD]: 1, B }\end{array}$ & $\begin{array}{ll}\text { Relation[f, g]: } & 1, \mathrm{R} \\
\text { Relation[A,f]: } & 2, \mathrm{~B} \\
\text { Relation[AB, CD]: } & 3, \mathrm{O}\end{array}$ \\
\hline $\begin{array}{l}(-3,0), \\
3), f= \\
\text { Line }[\mathrm{C},\end{array}$ & $\begin{array}{ll}\text { Relation[f, g]: } & 1, \mathrm{R} \\
\text { Relation[A,f]: } & 2, \mathrm{~B} \\
\text { Relation[AB, CD]: } & 1, \mathrm{~B}\end{array}$ & $\begin{array}{ll}\text { Relation[f, g]: } & 1, \mathrm{R} \\
\text { Relation[A,f]: } & 3, \mathrm{O} \\
\text { Relation[AB, CD]: } & 3, \mathrm{O}\end{array}$ \\
\hline $\begin{array}{l}\mathrm{A}=(-3,3), \mathrm{B}=(-3,0) \\
\mathrm{f}=\mathrm{Line}[\mathrm{A}, \mathrm{B}] \text { After } \\
\text { creating the above } \mathrm{C}= \\
(-3,-3)\end{array}$ & 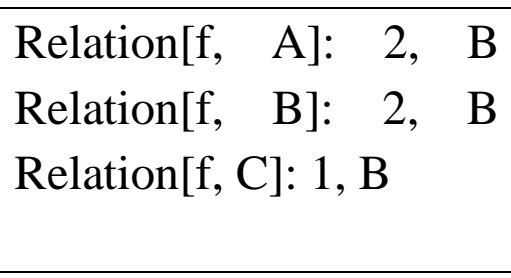 & 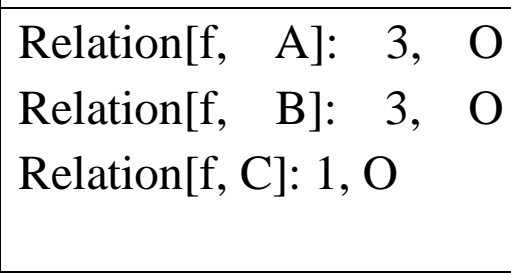 \\
\hline
\end{tabular}

R: Recio B: Botana O: OpenGeoProver

WU 1: But generally not correct 2 : Always correct 3 : Probably generally correct

In Table 2, although instabilities appeared, such as the change in the certification result depending on whether 0 is included in the coordinates of each point, such a phenomenon could not be confirmed at this time. [Your intended meaning is unclear. Please explain.] Moreover, in the behavior of OpenGeoProver, Table 2 gave the output "Probably generally correct", but this output could not be confirmed. [Your intended meaning is unclear. How are you "confirming" the output? Please explain.] Thus, continuous development of the prover is recommended. 


\section{Efforts to expand functions}

The efforts thus far confirmed that some processing is being performed by the prover being called, and, from the time of the report at the beginning of 2017, further changes in the implementation it were confirmed to have occurred. Here, we decided to investigate concrete program contents and investigate the status of the prover. In this section, we consider the contents of ver. 5.0.366, which was distributed around June 2017 and is older than the version considered thus far.

\subsection{How to change the Japanese notation of the UI dialog}

First, we checked the flags used in internal processing and examined whether the dialog of the UI displayed on the screen can be rewritten according to the situation.

The displayed Japanese information is stored by Unicode encoding. When Unicode encoding is applied to the Japanese in the UI output and a search of the entire program code is performed, it is possible to confirm the parts in which Japanese is used.

Here, we conducted an investigation of the expression "But generally not correct"(In fact, Japanese string to the same meaning as this), which was confirmed in the previous section. When converting this expression to Unicode, it becomes a character string starting with the expression ’¥u3057¥u304b¥u3057¥u4e...”. A search for this character string revealed that the string was con-firmed to be used in several parts in the program. The file containing Japanese in ver. 5.0.366 and its path are as follows:

/desktop/src/nonfree/resources/org/geogebra/desktop/properties/menu ja.properties

/web/src/nonfree/resource/org/gepgebra/web/pub/js/properties keys ja.js

These two files contain the following notation, and it is possible to check corresponding words in correspondence with character strings used in the original program:

”ButNotGenerallyTrue”:(¥u3057¥u304b¥u3057¥u4e. . . 
Thus, it was confirmed that the expression "But generally not correct" is used as the parameter "ButNotGenerallyTrue" in the program.

Next, by rewriting the part of menu ja.properties, we confirmed that the screen display will be updated. Therefore, we decided to temporarily replace the output "But generally not correct" with the expression "Correct in this figure" and continue the investigation.

\subsection{How to insert text in comments}

When compiling and running GeoGebra from source code on Eclipse, the state output can be obtained at the Eclipse console. This is also true for the prover. Although internal information on operation can be obtained, it is difficult to grasp at a glance the behavior of the prover. Thus, we confirm a method of freely inserting comments. A comment can be output to the console by inserting the following syntax:

Log.debug("Characters to display");

Using this syntax, output can be obtained in the form of adding information of the method being considered, such as the number of lines of the corresponding Log.debug. Next, an example of the output is shown.

0:08:36.416 DEBUG:

org.geogebra.common.kernel.prover.ProverBotanasMethod.prove[1691]:

-(BotanasMethod reply is incomplete) cannot reliably tell if the statement is really false

This is the operation time and the debug message. The strings after the "-" symbol have been prepared in advance as character strings to be displayed (The part surrounded by "()" is actually, Japanese string to the same meaning).

Here, we output the processing status of the branch processing performed by ProverBotanasMethod, in which Log.debug is embedded, in the form of a comment in the code. 


\subsection{Behavior of the prover as indicated by inserting comments}

As a result of checking the operation status by inserting comments, the prover seems to perform the operation as shown below.

1. Calculate numerically (before Prover operation): common.cas.giac.CASgiacB

2. Perform preprocessing: org.geogebra.common.kernel. Relation. Check

Generally, org.geogebra.common.util.Prover

3. Select Prover Engine to use:

org.geogebra.common.util.Prover.callEngine

4. Evaluate with the selected Prover Engine.

5. Transition to 6 if True and 3 if False.

6. Display of Proof result.

"Prover.java" operates as the core of the prover, and many classes are arranged this Java code to the axis.[Your intended meaning is unclear. Please explain.] The proof result is stored in the variable "ProofResult", and, by searching this variable, it is possible to confirm the class related to the proof. The engines that can be used in this case are listed in "publicenumProverEngine", and the setting including the boot order is implemented using the "public Prover ()" method of "Prover.java". In the standard state, the mode for automatically selecting the engine of the Prover is used, and the three engines "RECIOS PROVER", "BOTANAS PROVER", and "OPENGEOPROVER WU" are stored in an array so that they are used in this order. A program expanded to embed a message indicating the situation in Log.debug by referring to a comment statement described in the original Java code, or the like, in which the same syntax as that confirmed in Section 3 was input, and its operation status were examined. The behavior result is shown in Table 3. 
Table 3 Behavior of the prover in ver.5.0.366

\begin{tabular}{|c|c|c|c|}
\hline Syntax & Run Prover and Order & Result & Circumstances \\
\hline Relation[f, g] & $\begin{array}{l}\text { Recio } \rightarrow \text { End Screen } \\
\text { output is } \mathrm{f} \text { and } \mathrm{g} \text { are } \\
\text { parallel "Correct in this } \\
\text { figure" }\end{array}$ & False & $\begin{array}{lr}\text { In } & \text { RecioProver } \\
\ulcorner & \text { STATEMENT IS } \\
\text { FALSE }\rfloor & \end{array}$ \\
\hline $\begin{array}{l}\text { Relation[A, } \\
\text { f ] }\end{array}$ & $\begin{array}{l}\text { Recio } \rightarrow \text { Botana } \rightarrow \text { End } \\
\text { Screen output is A is on } \\
\mathrm{f} \text { "Always correct" }\end{array}$ & True & $\begin{array}{l}\text { In } \\
\text { RecioProver Statement } \\
\text { acquisition failed } \\
\downarrow \\
\text { In } \quad \text { BotanaProver } \\
\ulcorner\quad \text { STATEMENT IS } \\
\text { TRUE }\rfloor\end{array}$ \\
\hline $\begin{array}{l}\text { Relation[AB, } \\
\text { CD] }\end{array}$ & 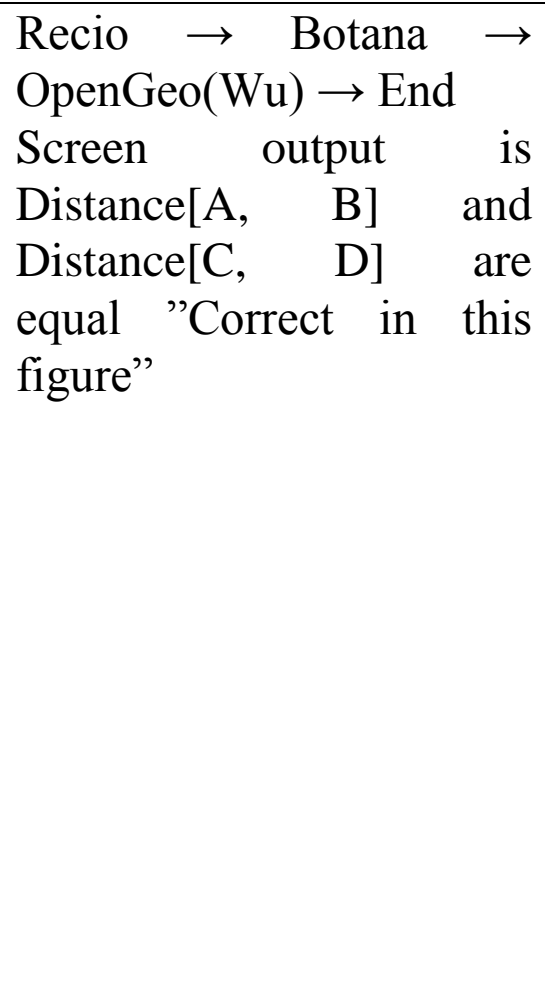 & $?$ & $\begin{array}{l}\text { In } \\
\text { RecioProver Statement } \\
\text { acquisition failed } \\
\downarrow \\
\text { In } \quad \text { BotanaProver } \\
\ulcorner\quad \text { statement is } \\
\text { UNKNOWN }\rfloor \\
\downarrow \\
\text { In OPENGEOPROVER } \\
\text { WU "Failed in reading } \\
\text { input geometry theorem" } \\
\downarrow \\
\ulcorner\quad \text { STATEMENT IS } \\
\text { FALSE }\rfloor\end{array}$ \\
\hline
\end{tabular}


All of the syntaxes were judged to be "correct" at the numerical check stage. However, Relation[f,g] completed processing immediately after the Recioprover made a "False" judgment, and the output was "Correct in this figure" ("But generally not correct" in the original notation). For Relation[AB,CD], although Recio, Botana, and OpenGeoProver Wu were run, Recio and OpenGeoProver could not process the syntax, and processing was interrupted at the reading stage. Although Botana was run, it was judged that it was undecidable, the final judgment result to transition with UNKNOWN, and it was finally decided to be FALSE.

\section{Conclusion}

Thanks to these efforts, although sufficient content analysis was not performed for the prover, overall, the use of expressions appears to be appropriate. Specifically, each prover appears to be implemented as an independent method at the time of calling, but looking at the actual internal operation, there is a code to call the Botanaprover from the Recioprover, and so on, which indicates that one research team is constructing two methods through various means. Although it is possible to change the starting order of the prover, GeoGebra wiki states that "End users had better not change the order". As such, there is expected to be a correlation between the Recio and Botanaprovers, even though this is not confirmed at this time. Moreover, although the reason was sufficiently investigated, as inferred from the output, even if the operation is not specified, the result is output after Botanaprover is manipulated again at the end of the proof. Given the status of such a prover, in order to handle the proof problem using GeoGebra, the behavior status of the prover should be checked and the knowledge of how to define points and lines should be deepened so that the prover works properly. Thus, a deeper examination into which types of proof problem can be solved appears to be necessary. On the other hand, since the prover is under development, in the short term, we will also consider options that involve cooperation between software and an external proving function. In the long term, we will also consider options to continue working after waiting for progress of the prover. 


\section{References}

[1] How to Solve It: A New Aspect of Mathematical Method (Princeton Science Library),

Princeton Univ. Pr., pp. 155-162, 2014.

[2] Theorem Proving, GeoGebra Developer Wiki, https://dev.geogebra.org/trac/wiki/TheoremProving, Viewing on November 10, 2017.

[3] Fumiya Iwama and Masanori Hukui, The Build and the proving of GeoGebra,

Memoirs of Konan University. Intelligence \& Informatics Series, in Japanese, Vol. 9,

No. 2, pp. 143-159, 2016. 